\title{
PERENCANAAN SISTEM INSTALASI HIDRANT PADA UNIVERSITAS ISLAM KALIMANTAN
}

\author{
(1)Khairil Anwar,, (2)Muhammad Firman, ${ }^{(3)}$ Muhammad Irfansyah \\ (1)(2)(3)Teknik Mesin, Fakultas Teknik, Universitas Islam Kalimantan MAB \\ JI. Adhiyaksa No. 2 Kayu Tangi, Banjarmasin \\ Email : firmanuniska99@gmail.com
}

\begin{abstract}
Abstrak
Fire Hydrant System adalah suatu sistem pemadam api yang dioperasikan secara manual oleh operator (manusia) dengan menggunakan media pemadamnya air dan disepanjang instalasi pempipaan mengandung air bertekanan sampai pada titik Hydrant Valve, Hose reel, Hydrant Pillar atau perangkat lainnya. Suatu sistem hidrant tak terlepas dari kinerja pompa yang dimana pompa adalah sebagai penggerak dari sistem hidrant itu sendiri. Khususnya untuk bangunan gedung, pemilihan jenis dan kapasitas pompa dapat ditentukan setelah mengetahui karakteristik dari gedung itu sendiri.

Metode penelitian yang dipakai adalah metode perencanaan yaitu sebuah metode penelitian dengan cara mengukur luas area gedung bertingkat, menentukan rumusrumus perpipaan beserta head kerugiannya, mendesain sebuah rancangan instalasi hidrant beserta alat dan bahan yang dipakai. Setelah mengetahui data-data perencanaan sistem hidrant berupa : Jenis cairan : Air, masa jenis cairan : $1 \mathrm{~kg} / \mathrm{liter}$, temperatur cairan : $25^{\circ} \mathrm{C}$, Kapasitas $2400 \mathrm{~L} /$ menit, penggerak motor listrik, dan putaran $2900 \mathrm{rpm}$. Didapat hasil perhitungan instalasi pompa hidrant adalah kerugian total yang terjadi di sepanjang pipa isap adalah : $17,55 \mathrm{~m}$, kerugian total yang terjadi di sepanjang pipa tekan adalah : 36,05 $\mathrm{m}$, head total pompa : $121 \mathrm{~m}$, putaran spesifik pompa : 23,96, efesiensi pompa sebesar $80 \%$, dan daya pompa sebesar : 6,05 Hp.
\end{abstract}

Kata Kunci : Sistem pompa hidrant, perencanaan hidrant, perhitungan instalasi hidrant

\begin{abstract}
Fire Hydrant System is a fire extinguishing system that is operated manually by the operator (human) A system hidrant inseparable from the performance of the pump where the pump is as a driver of hidrant system itself. Especially for buildings, the selection of the type and capacity of the pump can be determined after knowing the characteristics of the building itself.

The research method used is a method of planning is a research method by measuring the area of multi-storey buildings, determine formulas and their piping head loss, designing an installation design hidrant along with the tools and materials used After knowing the data system planning hidrant form: Type of liquid: water, density of liquids: $1 \mathrm{~kg} /$ liter, the liquid temperature: $25^{\circ} \mathrm{C}$, capacity of $2400 \mathrm{~L} / \mathrm{min}$, an electric motor, and a round of $2900 \mathrm{rpm}$. The result of calculation hidrant pump installation is a total loss that occurs along the suction pipe is: $17.55 \mathrm{~m}$, total losses that occur along the pipeline tap are: $36.05 \mathrm{~m}$, total head pumps: $121 \mathrm{~m}$, specific rotation pump: 23 96, pump efficiency by $80 \%$, and a pump power of: $6.05 \mathrm{Hp}$.
\end{abstract}

Keywords: Hidrant pump system, hidrant planning, installation calculation hidrant 


\section{PENDAHULUAN}

Saat perkembangan bangunan semakin pesat diseluruh dunia diantaranya bangunan gedung - gedung bertingkat, bangunan pendidikan, rumah sakit, rumah ibadah, serta perumahan untuk kehidupan manusia dalam menjalankan aktifitasnya. Dalam hal ini seluruh bangunan tersebut harus memperhatikan atau mempertimbangkan faktor - faktor kejadian yang tidak diinginkan seperti musibah yang disebabkan oleh faktor alam atau faktor manusia diantaranya gempa bumi, kebakaran, banjir, pemanasan global dan lain - lain sehingga kita mengetahui pencegahan sesuai dengan prosedur yang berlaku.

Melihat permasalahan di atas penulis menitik beratkan kepada masalah kebakaran bangunan, mengingat besarnya kerugian yang diakibatkan oleh kebakaran dan terbatasnya kemampuan peralatan pencegahan dan penanggulangan kebakaran yang dimiliki oleh Universitas Islam Kalimantan. Maka untuk bangunan Universitas Islam Kalimantan perlu memiliki sistem peralatan pencegahan kebakaran yang otomatis serta memenuhi persyaratan pencegahan dan penanggulangan kebakaran yang ditetapkan oleh Pemda setempat, seperti pemasangan alat pemadam kebakaran otomatis berupa sprinkler system, hydrant system dan pemadam api ringan. Oleh sebab itu, perlu dipelajari suatu system instalasi pipa pemadam kebakaran secara terpadu dan tidak melanggar standar nasional dan internasional. Kebakaran dapat menimbulkan berbagai macam kerugian dan korban manusia yang sampai saat ini masih sering terjadi di perumahan maupun fasilitas- fasilitas umum. Universitas Islam Kalimantan terletak di dalam kawasan Kayu Tangi Jl. Adhyaksa No. 2 Kota Banjarmasin Kalimantan Selatan. Gedung ini merupakan salah satu bangunan tertinggi di Jl.Adhyaksa Yang tidak terlepas dari resiko bahaya kebakaran, sehingga upaya-upaya untuk mencegah sangat penting dilakukan.

\section{METODE PENELITIAN}

Metode penelitian yang dipakai adalah metode perencanaan yaitu sebuah metode penelitian dengan cara mengukur luas area gedung bertingkat, menentukan rumus-rumus perpipaan beserta head kerugiannya, mendesain sebuah rancangan instalasi hidrant beserta alat dan bahan yang dipakai. Perencanaan ini dilaksanakan dalam beberapa tahap yaitu tahap perencanaan, tahap pengumpulan data, tahap perhitungan dengan rumus yang ada di referensi, dan analisis data.

Dalam perencanaan hydrant, terlebih dahulu harus diketahui spesifikasi dan jenis bangunan yang akan digunakan. Hal ini untuk mencegah terjadinya kesalahan dalam pemasangan instalasi hydrant dan pemilihan jenis pompa juga faktor-faktor yang dapat menimbulkan bahaya terjadinya kebakaran yang disebabkan oleh konstruksi dari bangunan tersebut.

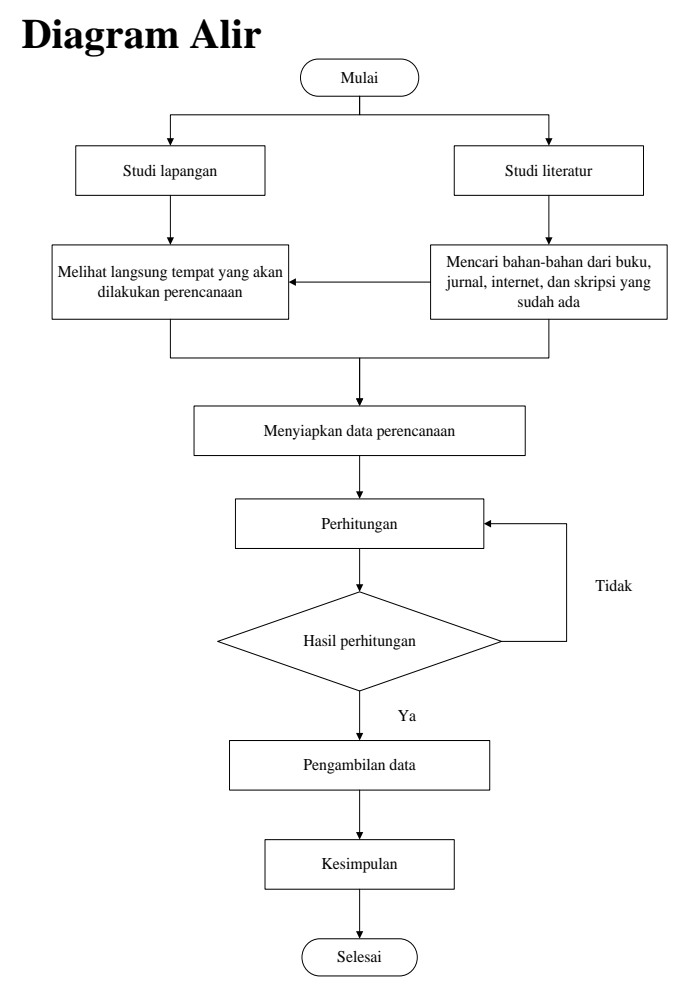


HASIL DAN PEMBAHASAN

Total kerugian pada pipa isap

Htot $=4,89+2,67+0,93+9,07$

$$
=17,55 \mathrm{~m}
$$

Total kerugian pada pipa tekan

Htot $=24,44+1,24+5,59+4,47+$ 0,31

$$
=36,05 \mathrm{~m}
$$

\section{Head statis pompa}

$\mathrm{h}_{\mathrm{a}}=20-(-2)=22 \mathrm{~m}$

\section{Head total pompa}

$\mathrm{H}_{\text {pompa }}=h_{a}+\Delta h_{p}+h l+\frac{V d^{2}-V s^{2}}{2 g}$

$\mathrm{H}_{\text {pompa }}=22+45+54+$

$$
\frac{4,936^{2}-4,936^{2}}{2.9,8}
$$

$\mathrm{H}_{\text {pompa }}=121 \mathrm{~m}$

\section{Putaran spesifik}

$$
\begin{aligned}
\mathrm{n}_{\mathrm{s}} & =\frac{n \sqrt{Q}}{H} \\
\mathrm{n}_{\mathrm{s}} & =\frac{2900 \sqrt{0,04}}{121} \\
& =23,96 \mathrm{rpm}
\end{aligned}
$$

Dari putaran didapat, maka bentuk impeller adalah :

$\mathrm{n}_{\mathrm{s}}=(12-35)$, adalah impeller jenis radial.

\section{Efesiensi pompa}

Berdasarkan grafik diatas dengan $\mathrm{Q}=$

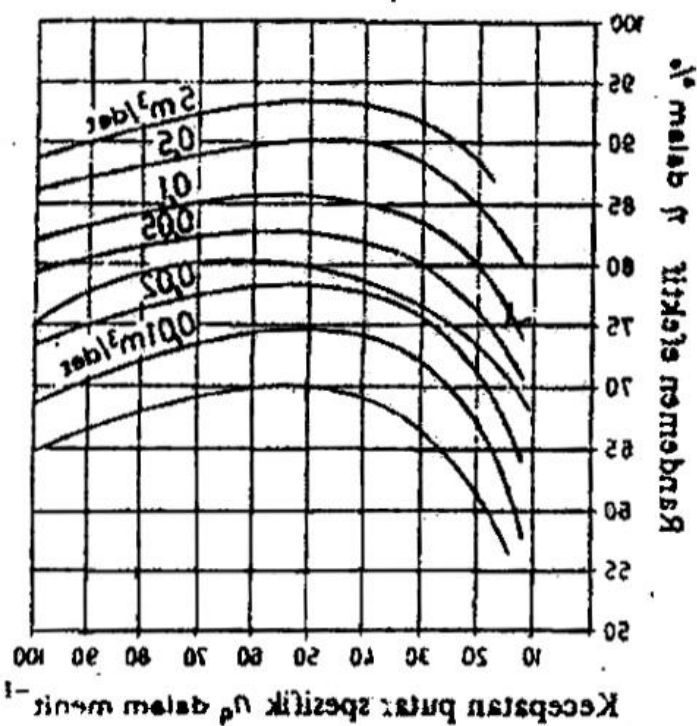

$0,04 \mathrm{~m} 3 / \mathrm{s}$ dan putaran spesifik (ns) $=$ 23,96 rpm maka diperoleh efisiensi pompa $(\mathrm{np})=80 \%$.

\section{Daya fluida}

$$
\begin{aligned}
\mathrm{Pw} & =p \cdot \mathrm{Q} \cdot \mathrm{H} \\
& =1000 \times 0,04 \times 121 \\
& =4840 \mathrm{~W} \\
& =4,84 \mathrm{Kw}
\end{aligned}
$$

\section{Daya pompa}

$$
\begin{aligned}
P & =\frac{P w}{n p} \\
& =\frac{4,84}{80 \%} \\
& =6,05 \mathrm{Hp}
\end{aligned}
$$

\section{KESIMPULAN}

Berdasarkan hasil perhitungan atas uaraian dan perencanaan yang telah dilakukan dapat disimpulkan bahwa :

1. Jenis pompa yang digunakan untuk instalasi hidrant adalah jenis pompa Centrifugal End Suction, merek Grundfos dengan kapasitas 2400 $1 /$ men.

2. Berdasarkan hasil perhitungan Head Total Pompa diperoleh hasil $121 \mathrm{~m}$

3. Kerugian total yang terjadi di sepanjang pipa isap adalah : 17,55 $\mathrm{m}$

4. Kerugian total yang terjadi di sepanjang pipa tekan adalah : 36,05 $\mathrm{m}$

5. Berdasarkan hasil perhitungan putaran spesifik pompa, maka didapat hasil 23,96 rpm dan efesiensi pompa adalah $80 \%$.

6. Berdasarkan hasil perhitungan daya pompa , maka didapat hasil 6,05 Hp.

\section{REFERENSI}

[1] M. Orianto, W.A Pratikto. 1984. Mekanika Fluida I. Surabaya.

[2] Robert J. Kodoatie. 2009. Hidrolika Terapan Aliran pada Saluran Terbuka dan Pipa. Yogyakarta.

[3] SKBI-3.4.53.1987. Panduan Pemasangan Sistem Hidrant Untuk 
Pencegahan Bahaya Kebakaran Pada Bangunan Rumah dan Gedung. Departemen Pekerjaan Umum.

[4] Sularso, Haruo, Tahara. 2004. Pompa dan Kompresor. Pemilihan, pemakaian, dan pemeliharaan. Jakarta

[5] http://disnaker.jatimprov.go.id/index .php. Standar Pelayanan Higiene Perusahaan, Kesehatan dan Keselamatan Kerja.

[6] http://enveng.undip.ac.idenveng@u ndip.ac.id ( Judul : Apar (Alat Pemadam api Ringan) dan Instalasi Hydrant sebagai salah satu upaya pencegahan dan penanggulangan kebakaran di area pabrik PT. Petrokimia Gresik ).

[7] http://jurnal.unimus.ac.id-jurnal vol. 7 no. 1 juni 2008 issn : $1693-3451$.

[8] http://www.bentley.com/enus/promo/hm+solutions/water+eboo k.html

Perencanaan Kontrol Start Otomatis Pompa Hydrant di Politeknik Negeri Bali.

[9] http://www.pipeflow.co.uk,"pipeflo wexpert",Software.2006 Judul : Evaluasi Fire Protection System pada Fuel Supply System, Utility Work Menggunakan Software Pipe Flow Expert (Study Kasus PT. Pertamina DPPU Juanda) 